\title{
APPLICATION OF THE NATURAL CELLULOSIC SUPPORTS FOR THE TREATMENT OF THE INDUSTRIAL EFFLUENTS
}

\author{
Andreea BONDAREV \\ Petroleum-Gas University of Ploiesti, Faculty of Petroleum Processing and Petrochemistry, Chemistry \\ Department, 39 Bucharest Blvd., 100680, Ploieşti, Romania \\ e-mail: andreeabondarev@yahoo.com
}

\begin{abstract}
Wastewater treatment is one of the most important concerns of the research studies in the field of environmental protection. The current study relates to the removal of Crystal violet dye from aqueous solutions through adsorption experiments onto natural cellulosic supports.

Various waste materials that have in their composition lignocellulose are adsorbent supports with low costs for the removal of heavy metal ions and dyes from aqueous solutions.

The use of chemically modified sawdust to obtain an inexpensive adsorbent for removing the Crystal violet dye $(C V)$ from synthetic aqueous solutions has been presented in this research paper. The influence of some important parameters such as: initial dye concentration, adsorbent dose, contact time and temperature on adsorption efficiency for this dye removal have been studied. The Freundlich, Langmuir and Temkin mathematical models have been used to evaluate the data of Crystal violet adsorption from aqueous media using wood sawdust.

The research study shows that beech wood sawdust (Fagus sylvatica), as an agricultural waste which is readily available and relatively inexpensive has the potential to be an applicable alternative adsorbent for Crystal violet dye removal from industrial effluents.
\end{abstract}

KEYWORDS: adsorption, sawdust, dyes, removal, agricultural wastes

\section{Introduction}

Discharge of industrial effluents containing hazardous components, such as phenolics, heavy metals and dyes, even at low concentrations produce a negative impact on the environment $[1,2]$. Dyes are notorious organic contaminants that can be discharged into the environment during textile, dye, leather, paints and paper manufacturing [1, 3, 4].

Due to toxicity, increasing the content of industrial sludge affects water bodies and finding environmentally friendly and economically accessible treatment methods is a priority [1].

Some industry domains such as leather tanning, food, paper, plastics production, cosmetics, printing rubber and textile demand a large amount of synthetic dyes. Due to their chemical structure and large-scale production and applications, synthetic dyes present serious health risks and they can also cause environmental pollution [5-8].
Treatment of wastewater by adsorption is one of the most researched and used methods, in order to eliminate priority pollutants, such as dyes, phenolic compounds and heavy metals. Granular activated carbon has been used successfully as adsorbent support, but it is cost-prohibitive, because it requires complexing agents to improve the capacity of adsorption for various contaminants. This aspect has led to research studies for cheaper adsorbent substitutes derived from biomass, such as agricultural and wood waste [1, 4-7]. The need to use alternative methods of water treatment, with widespread applicability, has led to a new area of interest: green technology, which has addressed specific procedures for environmental sustainability by minimizing pollution and using non-renewable resources [1, 8, 9].

Different natural waste materials such as citrus peel, almond shells, coconut shell, coffee and tea leave waste, olive leaves, carrot residue are promising material for biosorption of heavy metal ions and dyes from wastewater. Adsorbent materials of agricultural origin have in their chemical structure carbohydrate 
polymers -cellulose, hemi-cellulose and lignin, which act as active centres for synthetic dyes removal [5, 10-14].

There are many solid agricultural waste products that are available in large quantities, they are biodegradable and might be potential sorbents, due to their physico-chemical characteristics [2, 11, 12-15]. The adsorption of synthetic dyes on materials based on wood waste has been extensively studied in research projects. Wood waste can be burned, then fermented to obtain methane and alcohols, for the production of green energy, biofuels or certain industrial chemicals. Generally, sawdust is considered a timber-industrial waste, but it can become a valuable commodity, considering these directions: manufacturing, energy and agricultural utilization [9, 10]. Sawdust can be processed by advanced industrial methods, obtaining various products: adhesives, epoxy resins, fertilizers, adsorbent materials, floor tile, cleaning products and wood fillers [1, 10, 12]. It is well documented that the adsorption capacity of sawdust is significantly reliant on the species of wood $[5,14]$. Sawdust, as an agricultural waste which is highly efficient, readily available and relatively inexpensive, has the potential to be an applicable alternative adsorbent for dyes removal from synthetic domestic wastewater $[5,13,14]$.

This study showed that the beech wood sawdust could be employed as low-cost and effective sorbent for the removal of dyes from aqueous solution.

This study showed that chemically modified beech wood sawdust (Fagus sylvatica) could be used as effective sorbent for the removal of Crystal violet dye (CV) from synthetic aqueous solutions. The influence of some important parameters such as: initial dye concentration, adsorbent dose, contact time and temperature on adsorption efficiency for this dye removal have been studied.

The Langmuir, Temkin and Freundlich isotherms have been selected to study dye - adsorbent systems, in order to establish the optimum conditions for the adsorption of Crystal violet dye from aqueous solutions.

\section{Materials and methods}

\subsection{Dye solution}

The cationic dye Crystal violet $\left(\mathrm{C}_{25} \mathrm{H}_{30} \mathrm{~N}_{3} \mathrm{Cl}\right.$, $\lambda_{\max }=590 \mathrm{~nm}$ and $\mathrm{MW}=407.98 \mathrm{~g} / \mathrm{mol}$ ) was purchased from Sigma-Aldrich and used without further purification.

A stock solution of Crystal violet (CV) dye $(1000 \mathrm{mg} / \mathrm{L})$ was prepared by dissolving $1 \mathrm{~g}$ of dye in $1 \mathrm{~L}$ of deionized water. Different concentrations of Crystal violet $(\mathrm{CV})$ dye used in these experiments were prepared by diluting the stock solution with distilled water.

Calibration plots were made in the concentration range of $5-25 \mathrm{mg} / \mathrm{L}$. Dye concentrations were determined at the wavelength corresponding to the highest absorbance, $\lambda_{\max }=590 \mathrm{~nm}$. The UV-Vis Spectrophotometer (Jasco, model V-550) was employed to measure residual dye concentrations.<smiles>CN(C)c1ccc(C(=C2C=CC(=[N+](C)C)C=C2)c2ccc(N(C)C)cc2)cc1</smiles>

Fig. 1. Chemical structure of Crystal violet dye (CV) (source: https://www.sigmaaldrich.com)

\subsection{Preparation of the adsorbent support}

Beech wood sawdust (Fagus sylvatica) has been dried in an oven for $24 \mathrm{~h}$, at a temperature of $80{ }^{\circ} \mathrm{C}$ and then it was treated at room temperature with an aqueous solution of $\mathrm{NaOH} 1 \mathrm{~N}$. This adsorbent support has been oven dried for 8 hours at a temperature of $80{ }^{\circ} \mathrm{C}$, then it was ground and sieved, to get the homogenous particle sized material (between 0.3-0.6 $\mathrm{mm}$ in diameter). The characterization of the adsorbent material was described in a previous study [14].

\subsection{Adsorption studies}

The influence of some important parameters such as: initial dye concentration (60-150 mg/L), adsorbent dose (0.3-1 g), contact time (20-100 min) and temperature $\left(25-50{ }^{\circ} \mathrm{C}\right)$ on the adsorption efficiency for this dye removal have been studied. 
The cellulosic waste material was added into $100 \mathrm{~mL}$ of dye solutions with initial concentrations ranging between 60 and $150 \mathrm{mg} / \mathrm{L}$, respectively. The resulting suspensions have been shaken at a constant stirring rate $(200 \mathrm{rpm})$ for $1 \mathrm{~h}$ to reach equilibrium. After each experiment, the adsorbent was separated using Whatman 42 blue band filter paper and each sample of the treated aqueous solution has been evaluated to detect the residual dye using UV-Vis spectrometry. The tests were repeated in duplicate.

Dye adsorbed per unit mass of the adsorbent $\left(q_{e}\right.$, $m g / g$ ) and percentage dye removal $(R \%)$ for all samples have been calculated using Eq. 1 and Eq. 2, respectively $[1-5,10-13]$.

$$
\begin{gathered}
q_{e}=\left(C_{0}-C_{e}\right) \frac{\mathrm{V}}{\mathrm{W}} \\
\% R=\frac{C_{0}-C_{e}}{C_{0}} \cdot 100
\end{gathered}
$$

where $C_{0}(\mathrm{mg} / \mathrm{L})$ is the initial concentration of Crystal violet dye, $C_{e}(\mathrm{mg} / \mathrm{L})$ is the final Crystal violet dye concentration, $V$ is the total volume of the solution (L) and $W$ is the weight of the adsorbent support ( $\mathrm{g}$ ).

The achieved results from investigating the effect of contact time, initial concentration of pollutant, adsorbent dose and temperature have been used to study the isotherm modeling of the adsorption process.

\section{Results}

\subsection{The effect of initial concentration}

The effect of the initial dye concentration on the adsorption rate has been determined from the dye solution containing $60 \mathrm{mg} / \mathrm{L}, 80 \mathrm{mg} / \mathrm{L}, 100 \mathrm{mg} / \mathrm{L}$ and $150 \mathrm{mg} / \mathrm{L}$. The adsorption experiments have been carried out at room temperature i.e., $22 \pm 2{ }^{\circ} \mathrm{C}$, the adsorbent amount was of $0.5 \mathrm{~g}$ and contact time 60 min, using an Orbital Shaker Incubator, at 200 $\mathrm{rot} / \mathrm{min}$.

a) Effect of initial dye concentration on sorption of Crystal violet dye

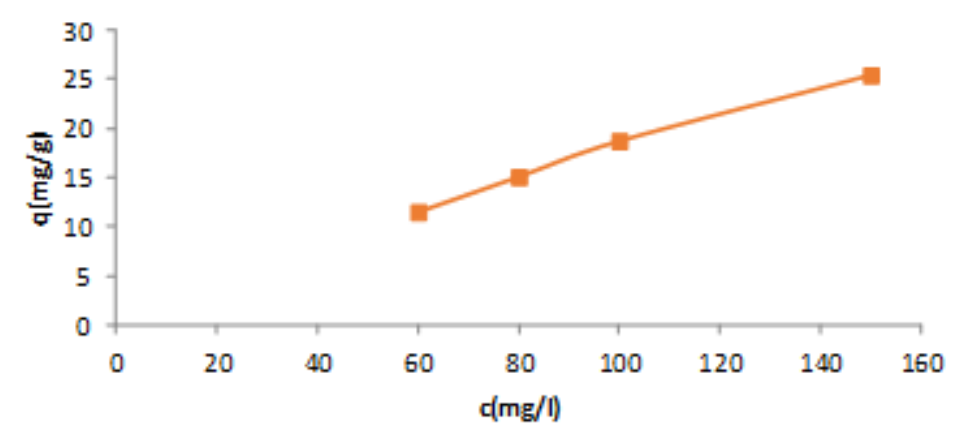

b) Effect of initial concentration on $\%$ Crystal violet dye removal

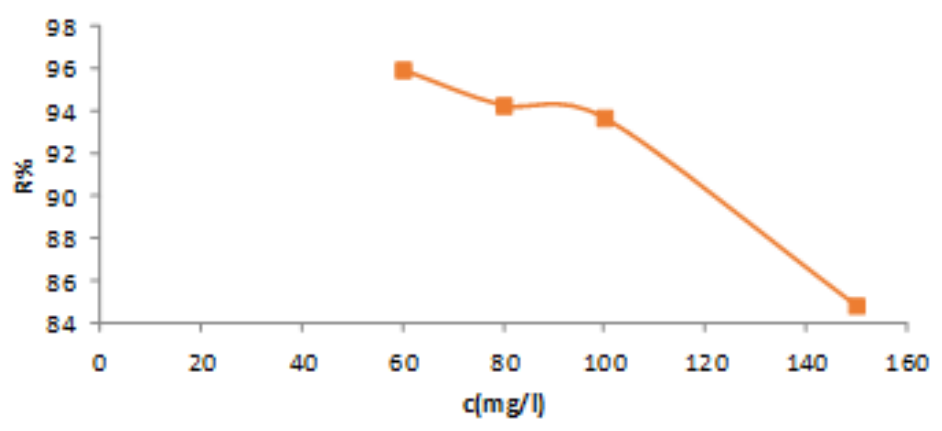

Fig. 2. The effect of initial concentration on Crystal violet dye adsorption on the beech wood sawdust (Fagus sylvatica)

The adsorption mechanism is dependent on the initial dye concentration: at low concentrations, the pollutant is adsorbed by specific sites of sawdust; increasing concentrations, the specific sites are saturated and the exchange sites are filled [10-13]. 


\subsection{The effect of adsorbent dose}

The effect of adsorbent dose has been investigated in the range $0.3-1 \mathrm{~g}$, for $100 \mathrm{mg}$ dye/L. The adsorption experiments have been carried out at the contact time $60 \mathrm{~min}$ and using an Orbital Shaker Incubator, at $200 \mathrm{rot} / \mathrm{min}$.

The increase in the removal efficiency by increasing the adsorbent dose can be due to the increment of active sites and sufficient surface for adsorbing of crystal violet molecules. The decrement in adsorption capacity with an increase in adsorption dose can be caused by various factors such as overlapping of active sites at high doses of adsorbent support $[1,8,14]$.

The quantity of adsorbent applied in the adsorption process is crucial because it influences the sorbent-sorbate ratio in the adsorption process and also in cost forecasting [4].

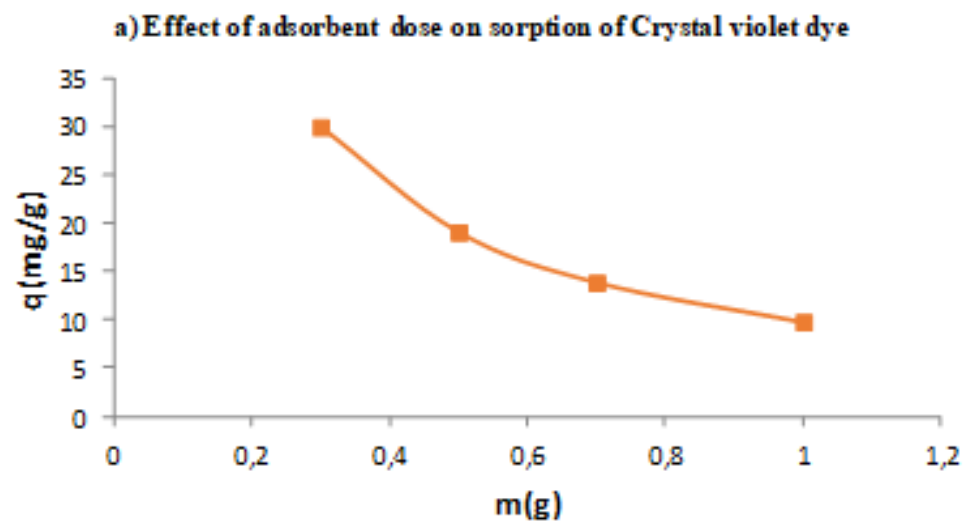

b) Effect of adsorbent dose on \% Crystal violet dye removal

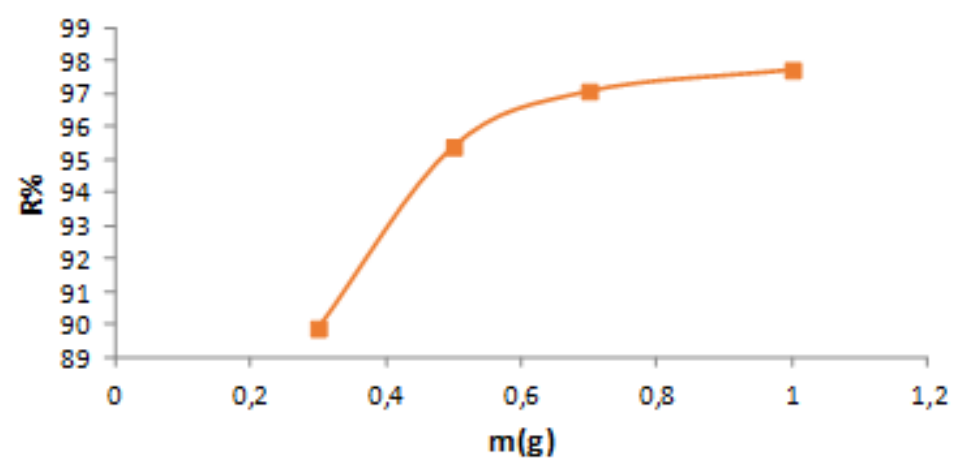

Fig. 3. The effect of adsorbent dose on the adsorption process of Crystal violet dye on chemically modified beech wood sawdust (Fagus sylvatica)

\subsection{The effect of temperature}

The effect of temperature on the adsorption rate has been investigated in the range $25-50{ }^{\circ} \mathrm{C}$, for 100 $\mathrm{mg}$ dye/L. The adsorption experiments have been carried out using the adsorbent amount of $0.7 \mathrm{~g}$, contact time $60 \mathrm{~min}$ and an Orbital Shaker Incubator, at $200 \mathrm{rot} / \mathrm{min}$.

Temperature has an important impact on the adsorption process. The experimental results showed that the adsorption capacity increased as temperature increased up to $50{ }^{\circ} \mathrm{C}$.

Temperature plays an important role in adsorption process because it influences mobility and solubility of dye molecules in aqueous solution and surface properties of adsorbent. Increase in temperature result in an increased rate of diffusion of dye molecules across the external boundary layer of the adsorbent particles and inside their internal pores $[3,8,9]$. 


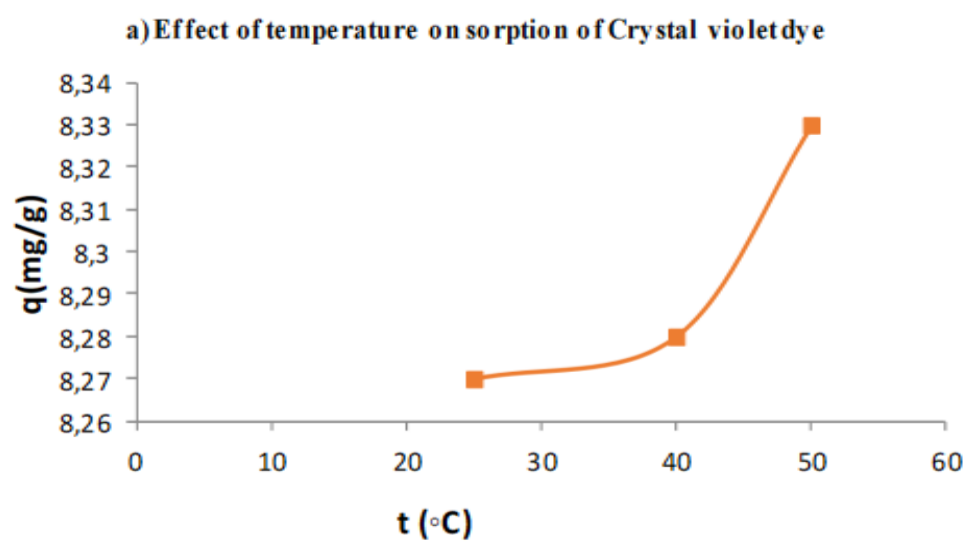

b) Effect of temperature on \% Crystal violet dye removal

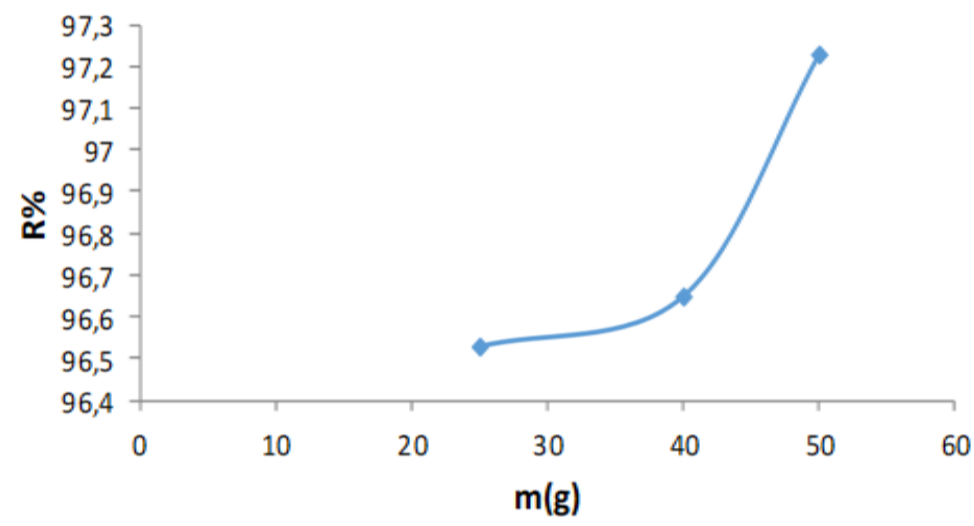

Fig. 4. The effect of temperature on the adsorption process of Crystal violet dye on chemically modified beech wood sawdust (Fagus sylvatica)

\subsection{The effect of contact time}

The effect of contact time on the adsorption rate has been investigated in the range of 20-100 $\mathrm{min}$, for $100 \mathrm{mg}$ dye/L. The adsorption experiments have been carried out using the adsorbent amount of $0.7 \mathrm{~g}$ and an Orbital Shaker Incubator, at $200 \mathrm{rot} / \mathrm{min}$.
Figure 5 shows the effect of contact time on the adsorption process of Crystal violet on wood sawdust powder and it clearly indicates that adsorption increased with the increase of the contact time.

The period of contact between the sorbent and biosorbate is very important in costing when designing a biosorption system for large scale application in an industry $[3,10]$.

a) Effect of contact time on sorption of Crystal violet dye

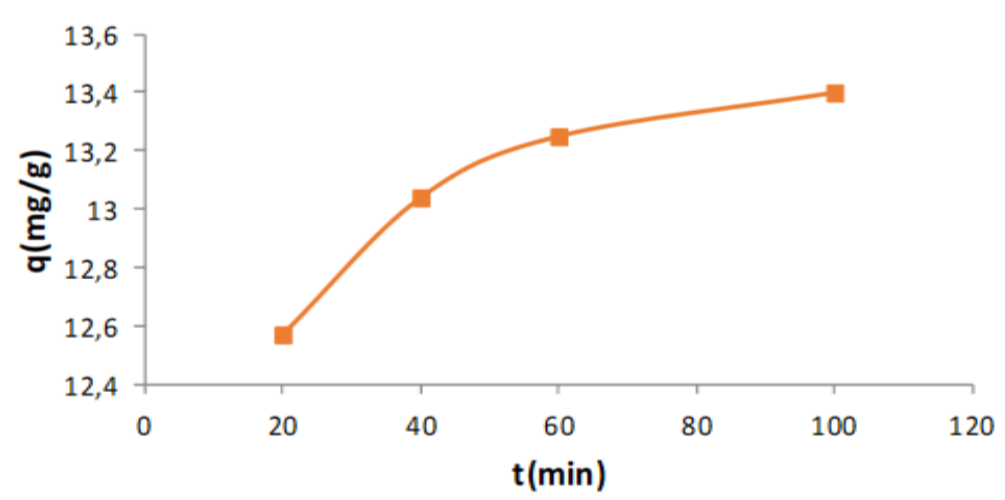


b) Effect of contact time on $\%$ Crystal violet dye removal

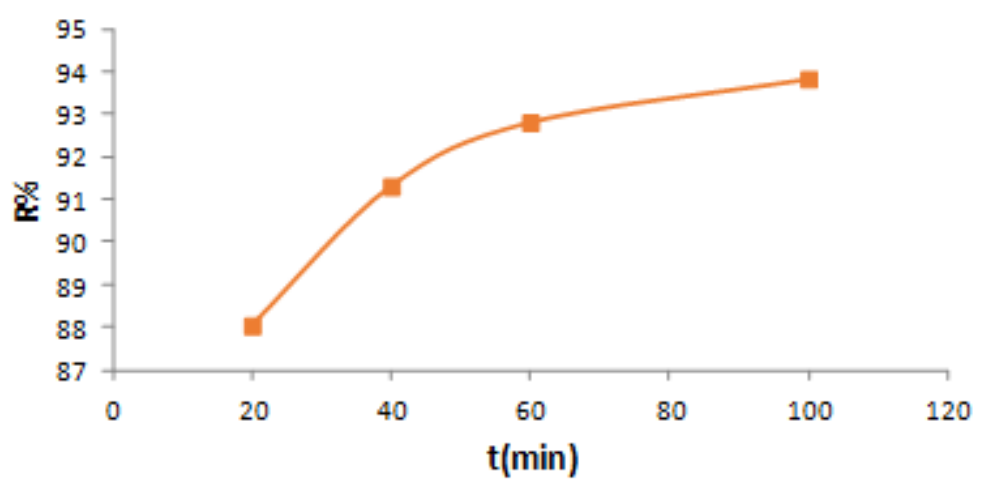

Fig. 5. The effect of contact time on the adsorption process of Crystal violet dye on chemically modified beech wood sawdust (Fagus sylvatica)

\section{Discussion}

\subsection{Isotherm study}

Adsorption isotherms are mathematical models that describe the distribution of the adsorbate species among the solid and liquid phases. The study of adsorption isotherms provides an effective perspective for determining the adsorption mechanism [5, 7-9]. An adsorption isotherm is a curve which describes the phenomenon governing the retention (or release) or mobility of a substance from aquatic media to a solid-phase, considering a constant temperature and $\mathrm{pH}[3,5-8]$.

Freundlich, Langmuir and Temkin adsorption isotherms have been used to evaluate the data of Crystal violet removal from aqueous media using chemically modified wood sawdust.

The isotherm expressions are given in Equations (3), (4) and (5) [3, 7-10].

$$
\text { Freundlich: } \quad q_{e}=K_{F} \cdot C_{e}{ }^{1 / n}
$$

where: $K_{\mathrm{F}}\left(\mathrm{mg} \mathrm{g}^{-1}\right)$ is the Freundlich constant related to the adsorption capacity; $1 / \mathrm{n}$ represents a parameter related the adsorption intensity; $\mathrm{q}_{\mathrm{e}}\left(\mathrm{mg} \mathrm{g}^{-1}\right)$ is the equilibrium adsorption concentration of dye per gram of adsorbent; $\mathrm{C}_{\mathrm{e}}\left(\mathrm{mg} \mathrm{L}^{-1}\right)$ represents the concentration of the solute in solution at equilibrium [3, 7-10].

$$
\text { Langmuir: } q_{e}=q_{m} \cdot K_{L} \cdot C_{e} / 1+K_{L} \cdot C
$$

where: $\mathrm{q}_{\mathrm{e}}\left(\mathrm{mg} \mathrm{g}^{-1}\right)$ represents the amount of solute adsorbed per amount of adsorbent; $\mathrm{C}_{\mathrm{e}}\left(\mathrm{mg} \mathrm{L}^{-1}\right.$ or mmol L ${ }^{-1}$ ) is the aqueous-phase concentration of adsorbate (mg/L) at equilibrium.; $q_{\mathrm{m}}\left(\mathrm{mg} \mathrm{g}^{-1}\right)$ represents the maximum adsorption capacity; $K_{\mathrm{L}}$ $(\mathrm{L} / \mathrm{mg})$ is the Langmuir constant related to the free adsorption energy $\left(\mathrm{L} \mathrm{mg}^{-1}\right.$ or $\left.\mathrm{L} \mathrm{mmol}^{-1}\right)$ [3, 7-10].

$$
\text { Temkin: } q=\frac{R T}{b} \ln \left(K_{T} \cdot C_{e}\right)
$$

where $K_{\mathrm{T}}\left(\mathrm{L} \mathrm{mg}^{-1}\right)$ and $b_{\mathrm{T}}(\mathrm{KJ} / \mathrm{mol})$ are Temkin isotherm constants linked with the adsorption heat and the equilibrium binding constant [3, 7-10].

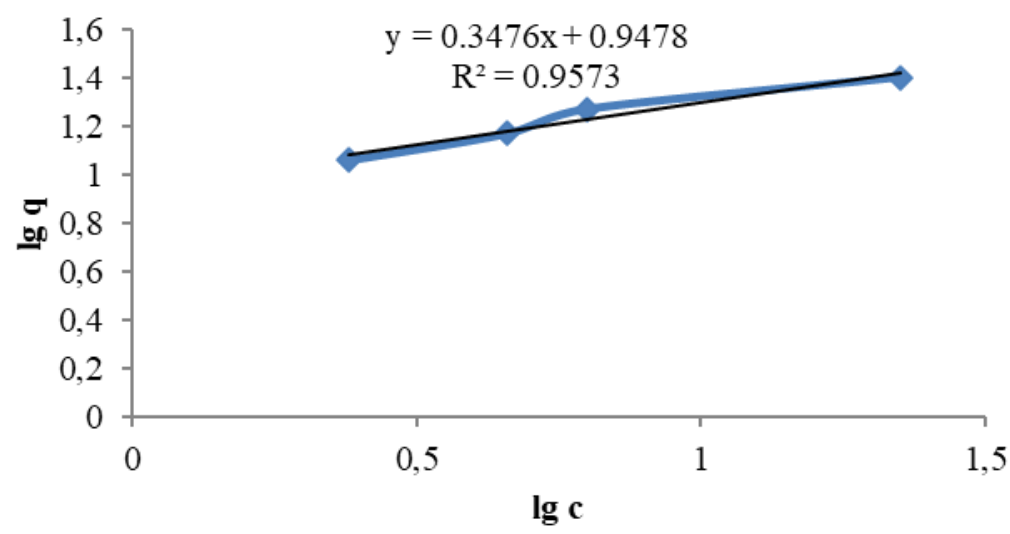

Fig. 6. The linearized Freundlich adsorption isotherm for the sorption of Crystal violet by beech wood sawdust (Fagus sylvatica) 


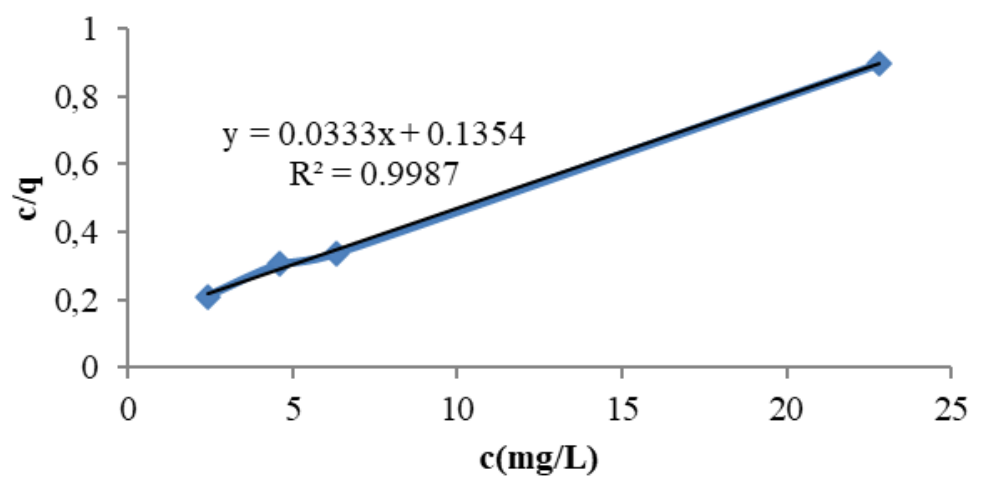

Fig. 7. The linearized Langmuir adsorption isotherm for the sorption of Crystal violet by beech wood sawdust (Fagus sylvatica)

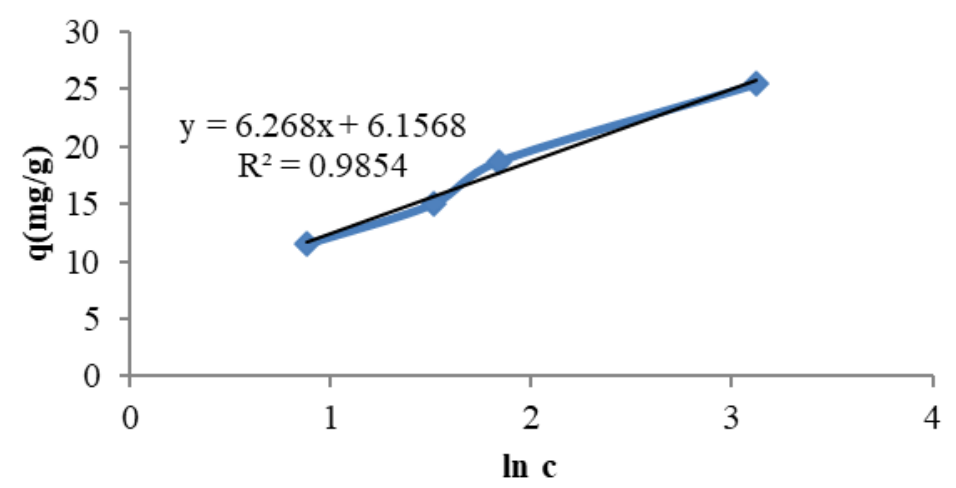

Fig. 8. The Temkin adsorption isotherm for the sorption of Crystal violet by beech wood sawdust (Fagus sylvatica)

The results suggest that Crystal violet dye has been favourably adsorbed by modified wood sawdust with high values of the correlation coefficient $\left(\mathrm{R}^{2}=\right.$ 0.9987), indicating that the Langmuir isotherm has been best fitted for the adsorption of dye on modified wood sawdust.

Langmuir isotherm model infers that the adsorption occurs at specific homogeneous sites on the adsorbent and it is used in many monolayer adsorption processes [3, 8-10]. It is noteworthy to point out that experimental data fitted well both Langmuir and the Temkin adsorption isotherms models indicating that both models are suitable for describing the adsorption equilibrium of this dye in the studied concentration ranges.

\section{Conclusions}

This paper is part of a series of works aiming at valorising sawdust for the removal of synthetic dyes from aqueous solution by adsorption method.

The use of adsorbents based on natural cellulosic supports for the removal of synthetic dyes from wastewater has many benefits, including the cost of investment and outstanding performance. This research study revealed that chemically modified beech wood sawdust (Fagus sylvatica) is a viable and affordable adsorbent for the adsorptive removal of Crystal violet dye from contaminated wastewater, with over $97 \%$ dye removal.

The effect of temperature, contact time, adsorbent mass and initial dye concentration has been investigated to evaluate the performance of modified wood sawdust for adsorption of Crystal violet from aqueous solutions.

The Langmuir, Temkin and Freundlich mathematical models were suitable to describe the equilibrium behavior of Crystal violet dye adsorption using modified beech wood sawdust. The experimental data showed the best fit to Langmuir model, with high correlation coefficient $\left(\mathrm{R}^{2}=0.9987\right)$ indicating that the model was appropriate to describe the adsorption process of Crystal violet dye onto beech wood sawdust (Fagus sylvatica), suggesting also the spontaneous nature of the process.

This study proved that sawdust, as an agricultural waste which is highly efficient, readily available and relatively inexpensive has the potential to be an applicable alternative adsorbent for Crystal violet dye removal from aqueous media. 


\section{THE ANNALS OF “DUNAREA DE JOS” UNIVERSITY OF GALATI \\ FASCICLE IX. METALLURGY AND MATERIALS SCIENCE \\ $\mathrm{N}^{\circ} .3$ - 2021, ISSN 2668-4748; e-ISSN 2668-4756 \\ Article DOI: https://doi.org/10.35219/mms.2021.3.08}

\section{References}

[1]. Saeed A., Sharif M., Iqbal M., Application potential of grapefruit peel as dye sorbent: Kinetics, equilibrium and mechanism of crystal violet adsorption, Journal of Hazardous Materials, 179, p. 564-572, 2010.

[2]. Amarasinghe B. M., Williams R. A., Tea waste as a low-cost adsorbent for the removal of $\mathrm{Cu}$ and $\mathrm{Pb}$ from wastewater, Chemical Engineering Journal, 132 (1-3), p. 299-309, 2007.

[3]. Wanyonyi W. C., Onyari J. M., Shiundu P. M., Adsorption of congo red dye from aqueous solutions using roots of eichhornia crassipes: kinetic and equilibrium studies, Energy Procedia, 50, p. $862-869,2014$

[4]. Oguntimein G. B., Biosorption of dye from textile wastewater effluent onto alkali treated dried sunflower seed hull and design of a batch adsorber, J. Environ. Chem. Eng., 3(4), p. 2647-2661, 2015.

[5]. Martins L., Vieira Rodrigues J., Herrera Adarme O. Sacramento Melo T., Gurgel L., Gil L., Optimization of cellulose and sugarcane bagasse oxidation: Application for adsorptive removal of crystal violet and auramine- $O$ from aqueous solution, Journal of Colloid and Interface Science, 494, p. 223-241, doi: 10.1016/j.jcis.2017.01.085, 2017.

[6]. Gilbert K., Wycliffe C., Joyce J., Esther N. M., Adsorption of toxic crystal violet dye using coffee husks: Equilibrium, kinetics and thermodynamics study, Scientific African, 5, p. 1-11, 2019.

[7]. Bombos D., Ganea R., Matei V., Marinescu C., Bondarev A., Mihai S., Natu T., Tamas I., Modified Bentonite for Purification of Dyeing Waste WaterRev, Chim., 65 (8), p. 976-982, 2014.

[8]. Lafi R., Rezma S., Hafiane A., Removal of toluidine blue from aqueous solution using orange peel waste (OPW), Desalin. Water Treat., 56(10), p. 1-12, 2014.
[9]. Razmovski R., Ciban M., Biosorption of $\mathrm{Cr}(\mathrm{VI})$ and $\mathrm{Cu}(\mathrm{II})$ by waste tea fungal biomass, Ecological Engineering, 34(2), p. 179186, 2008.

[10]. Rajeswari M., Revanth T., Aniruth A., Prasad B., Removal of Crystal Violet dye from aqueous solution using water hyacinth: Equilibrium, kinetics and thermodynamics study, ResourceEfficient Technologies, 3 (1), p. 71-77, 2017.

[11]. Hou S., Adsorption properties of pomelo peels against methylene blue in dye wastewater, Adv. Mater. Res., 634-638, p. 178-181, 2013.

[12]. Erfani M., Javanbakht V., Methylene Blue removal from aqueous solution by a biocomposite synthesized from sodium alginate and wastes of oil extraction from almond peanut, Int. J. Biol. Macromol, 114, p. 244-255, 2018.

[13]. Rominiyi O., Adaramola B., Ikumapayi O., Potential Utilization of Sawdust in Energy, Manufacturing and Agricultural Industry: Waste to Wealth, World Journal of Engineering and Technology, 05(03), p. 526-539, 2017.

[14]. Bondarev A, Gheorghe C. G, Gheorghe V., Bombos M., Removal of Dyes from Textile Wastewater Using Sawdust as Lowcost Biosorbent, Rev. Chim., 71 (3), p. 387-396, 2020.

[15]. Apafaian A. I., Proto A. R., Borz S. A., Performance of a mid-sized harvester-forwarder system in integrated harvesting of sawmill, pulpwood and firewood, Ann. For. Res., 60(2), p. 227241, doi: 10.15287/afr.2017.909, 2017.

[16]. Bello K., Sarojini B. K., Narayana B., Rao A., Byrappa K., A study on adsorption behavior of newly synthesized banana pseudo-stem derived superabsorbent hydrogels for cationic and anionic dye removal from effluents, Carbohydr. Polym., 181, p. 605-615, doi: 10.1016/j.carbpol.2017.11.106, 2018.

[17]. Monda L., M. K., Removal of Pb(II) ions from aqueous solution using activated tea waste: Adsorption on a fixed-bed column, Journal of Environmental Management, 90(11), p. 3266$3271,2009$. 